ORIGINAL ARTICLE

\title{
Climate and the prevalence of symptoms of asthma, allergic rhinitis, and atopic eczema in children
}

\author{
S K Weiland, A Hüsing, D P Strachan, P Rzehak, N Pearce, and the ISAAC Phase One Study \\ Group
}

Occup Environ Med 2004;61:609-615. doi: 10.1136/oem.2002.006809

See end of article for authors' affiliations .....................

Correspondence to: Prof. Dr. med. S Weiland, Department of Epidemiology, University of Ulm, Helmholzstr. 22, 89081 Ulm, Germany; stephan.weiland@ medizin.uni-ulm.de

Accepted 28 November 2003

\begin{abstract}
Aims: To investigate the association between climate and atopic diseases using worldwide data from 146 centres of the International Study of Asthma and Allergies in Childhood (ISAAC).

Methods: Between 1992 and 1996, each centre studied random samples of children aged 13-14 and 6-7 years (approx. 3000 per age group and centre) using standardised written and video questionnaires on symptoms of asthma, allergic rhinoconjunctivitis, and atopic eczema during the past 12 months. Data on long term climatic conditions in the centres were abstracted from one standardised source, and mixed linear regression models calculated to take the clustering of centres within countries into account. Results: In Western Europe (57 centres in 12 countries), the prevalence of asthma symptoms, assessed by written questionnaire, increased by $2.7 \%(95 \% \mathrm{Cl} 1.0 \%$ to $4.5 \%)$ with an increase in the estimated annual mean of indoor relative humidity of $10 \%$. Similar associations were seen for the video questionnaire and the younger age group. Altitude and the annual variation of temperature and relative humidity outdoors were negatively associated with asthma symptoms. The prevalence of eczema symptoms correlated with latitude (positively) and mean annual outdoor temperature (negatively).

Conclusions: Results suggest that climate may affect the prevalence of asthma and atopic eczema in children.
\end{abstract}

A potential role of climatic conditions in the aetiology of asthma and allergies has long been suspected. ${ }^{1-3}$ Most studies on the effects of climate, however, have investigated the association of short term variations in climatic or meteorological conditions with the occurrence or severity of symptoms of atopic diseases. For example, it has been shown that asthma exacerbations and hospital admissions are associated with season, falls in temperature or relative humidity, thunderstorms, and increases in exposure to air pollution or aeroallergens. ${ }^{4-11}$ Little is known, however, about the effect of long term climatic conditions on the prevalence of asthma.

Climate affects whole populations in given areas. Therefore its influences on the occurrence of atopic diseases can only be studied by ecological studies examining the relation between climatic conditions and rates of disease occurrence between populations. Until recently, such studies have been hampered because the necessary data were not available. Although a large number of prevalence studies had been carried out worldwide, most prevalence data were not comparable due to lack of standardised methods. Therefore, studies on the long term effects of climate were limited to comparisons of areas within countries. ${ }^{12-19}$ Most of these studies had low numbers of study centres and much less variation in climatic conditions than could be achieved by international comparisons. Thus, the value of the information generated by previous investigations is limited and it is difficult to draw firm conclusions.

The International Study of Asthma and Allergies in Childhood (ISAAC) has been initiated to facilitate worldwide comparisons of study populations. ${ }^{20}{ }^{21}$ Simple but valid study methods have been developed and successfully applied in 155 study centres around the world. ${ }^{22-25}$ The objective of this study was to investigate whether climate is associated with the prevalence of symptoms of asthma, allergic rhinoconjunctivitis, and atopic eczema in children.

\section{SUBJECTS AND METHODS}

\section{Study population}

The methods $\mathrm{s}^{20}$ and finding $\mathrm{s}^{22-25}$ of Phase One of ISAAC have been published in detail elsewhere. Briefly, the protocol required us to study at least 3000 children aged 13-14 years per study centre. Community based random samples using schools as sampling units were identified and invited to participate in the study. The children completed a self administered written questionnaire (WQ) on the occurrence and severity of symptoms of asthma, allergic rhinoconjunctivitis, and atopic eczema. The study was successfully completed in 155 study centres in 56 countries on six continents. It involved 463801 children in this age group and had a participation of more than $85 \%$ in most study centres. ${ }^{22} 24$

The ISAAC Phase One protocol included also a video questionnaire (VQ) to address concerns about problems with the translation of terms such as "wheezing" and "whistling in the chest" into different languages. ${ }^{20}{ }^{26}$ The video questionnaire showed five sequences of clinical asthma in different situations. After each sequence, the children were asked to specify whether and when their breathing had been like the person's in the video. This instrument was optional and was used in 99 study centres in 42 countries worldwide. ${ }^{23} 24$

Furthermore, the ISAAC Phase One protocol also involved 6-7 year old children. Again community based random samples with a sample size of 3000 were required. Parental questionnaires, analogous to those used in 13-14 year olds, were completed by the parents. The response rate was above $75 \%$ in most study centres. ${ }^{22}{ }^{24}$ Investigation of this age group 


\section{Main messages}

- In Western Europe (57 centres in 12 countries), the prevalence of asthma symptoms, assessed by written questionnaire, increased by $2.7 \% 195 \% \mathrm{Cl} 1.0 \%$ to $4.5 \%$ ) with an increase in the estimated annual mean of indoor relative humidity of $10 \%$.

- Altitude and the annual variation of temperature and relative humidity outdoors were negatively associated with asthma symptoms.

- The prevalence of eczema symptoms correlated with latitude (positively) and mean annual outdoor temperature (negatively).

was also optional and was completed in 91 study centres in 38 countries. All studies were completed between 1992 and 1996.

\section{Assessment of health outcome}

This analysis concentrates on the 12 months period prevalence of symptoms as assessed by the ISAAC core questionnaires. ${ }^{20}$ For asthma, the relevant question was: Have you (has your child) had wheezing or whistling in the chest in the last 12 months? (yes/no). For rhinoconjunctivitis, affirmative answers to the following two questions were required: In the last 12 months, have you (has your child) had a problem with sneezing or a running or blocked nose when you (he/she) did not have a cold or flu? (yes/no); In the past 12 months, has this nose problem been accompanied by itchy watery eyes? (yes/no). For eczema, affirmative answers to the following three questions were required: Have you (has your child) ever had an itchy rash which was coming and going for at least 6 months? (yes/no); Has your child had this itchy rash at any time in the last 12 months? (yes/no); Has this itchy rash at any time affected any of the following places: the folds of the elbows, behind the knees, in the front of the ankles, under the buttock, and around the neck, ears, or eyes? (yes/no). The 12 months period prevalence of wheezing as assessed by the video questionnaire used the first scene, which showed a girl with wheezing at rest, and the question on occurrence of such symptoms in the last 12 months. The symptom prevalence rates in the study centres were calculated based on these questions and were used for the subsequent analyses as outcome variables.

\section{Assessment of climatic conditions}

We abstracted standardised and comparable information on long term average climatic conditions in the different study areas from one source, the World weather guide. ${ }^{27}$ It includes data from measurement stations in or close to 146 of the 155 ISAAC study centres around the world. The following information is provided: latitude, altitude, and for each month the average daily maximum and minimum of the outdoor temperature and relative humidity. We calculated the monthly mean as the average of daily maximum and minimum. Furthermore, we calculated for each centre and for both the temperature and the relative humidity outdoors the annual mean, the annual variation (standard deviation of the annual mean), and the mean of the month with the lowest values. We also categorised centres according to whether there were months with a mean temperature below $0^{\circ} \mathrm{C}$ or a mean relative humidity below $50 \%$. In addition, an estimate of the indoor relative humidity was calculated for each study centre. First, an estimate of the absolute humidity was computed for each month using the mean of the outdoor

\section{Policy implications}

- These findings suggest that climate may affect the prevalence of asthma and atopic eczema in children.

- This may have implications for the assessment of potential health effects due to climate change.

temperature and of the outdoor relative humidity. Second, an estimate of the relative humidity at an indoor temperature of $20^{\circ} \mathrm{C}$ was derived on the basis of the computed absolute humidity outdoors using standard tables and formulas. ${ }^{28}$

\section{Statistical analysis}

The analyses were conducted separately for the two age groups, for all study centres worldwide and for the centres in Western Europe. These were located in Austria $(n=2$ centres), Belgium $(n=1)$, Finland $(n=3)$, France $(n=5)$, Germany $(n=2)$, Greece $(n=1)$, Ireland $(n=1)$, Italy $(n=13)$, Portugal $(n=4)$, Spain $(n=8)$, Sweden $(n=2)$, and the UK $(n=15)$. Mean and range of the climate variables and disease prevalence rates were calculated (table 1). Simple linear regression analyses were first applied to assess the association between climate and the prevalence of atopic diseases in the study centres.

However, many of the countries in which the ISAAC study had been conducted had more than one study centre. Because countries differ in many more aspects than climatic conditions it was felt important to take this nested structure in hierarchical models into account. Therefore multilevel models were calculated using Proc Mixed of the SAS Software. ${ }^{29}$ The specified model is a two level, random intercept, fixed slope model with the dependent variable modelled by the normality assumption..$^{30}$ The model allows for random deviations from the estimated overall prevalence for each country, but the influence of the climate variable is assumed to affect the prevalence non-differentially.

The results of the multilevel models differed substantially from those of the simple linear regression analyses that did not control for the location of centres within countries. The strongest effect was seen when analysing the association between the prevalence of asthma symptoms, assessed by written questionnaire, and the estimated indoor relative humidity in Western Europe (fig 1). The simple linear regression, ignoring country effects, found a statistically significant negative association (regression coefficient -0.34 ; $95 \%$ CI -0.58 to -0.10 ). The multilevel models, in turn, showed a statistically significant positive association (regression coefficient $0.27 ; 95 \%$ CI 0.10 to 0.45 ). The reasons for this discrepancy can be seen in fig 1 . Without taking the country effect into account, the simple regression analysis finds a negative association. However, within each country with at least two study centres there is in fact a positive relation between the estimated indoor relative humidity and the prevalence of asthma symptoms. Ignoring this strong country effect would yield spurious results. The multilevel models calculate estimates for the climate variables that take the fact that prevalence rates in countries may deviate from the estimated overall prevalence into account (fig 1). Therefore, we report only the results of the multilevel models. The regression coefficients express the change in prevalence rates (in absolute percent) if the exposure changes by one unit.

Because gross national product per capita (GNP) is associated with the prevalence of atopic symptoms worldwide, $^{31}$ the presented estimates of the association between 
Table 1 Characteristics of the study centres

\begin{tabular}{|c|c|c|c|c|}
\hline & \multicolumn{2}{|l|}{ Worldwide } & \multicolumn{2}{|l|}{ Western Europe } \\
\hline & $\begin{array}{l}13-14 \text { years } \\
\text { Mean (range) }\end{array}$ & $\begin{array}{l}\text { 6-7 years } \\
\text { Mean (range) }\end{array}$ & $\begin{array}{l}\text { 13-14 years } \\
\text { Mean (range) }\end{array}$ & $\begin{array}{l}\text { 6-7 years } \\
\text { Mean (range) }\end{array}$ \\
\hline Number of study centres & 144 & 81 & 57 & 26 \\
\hline Latitude (degrees) & $36.6(0.0$ to 69.0$)$ & $33.6(1.0$ to 59.0$)$ & $47.2(32.0$ to 69.0$)$ & $43.9(32.0$ to 59.0$)$ \\
\hline Altitude $(100 \mathrm{~m})$ & 1.7 (0.0 to 24.5 ) & $1.2(0.0$ to 23.1$)$ & $1.0(0.0$ to 6.6$)$ & $1.1(0.1$ to 6.6$)$ \\
\hline \multicolumn{5}{|l|}{ Climatic factors } \\
\hline Annual outdoor temperature $\left({ }^{\circ} \mathrm{C}\right)$ & $15.7(-1.3$ to 28.5$)$ & $17.4(1.8$ to 28.5$)$ & $12.3(-1.3$ to 18.5$)$ & 13.8 (6.6 to 18.5$)$ \\
\hline Annual outdoor relative humidity (\%) & $72.0(48.6$ to 87.6$)$ & $71.8(48.6$ to 87.6$)$ & 73.9 (57.0 to 83.1$)$ & $73.0(57.0$ to 83.1$)$ \\
\hline Annual indoor relative humidity at $20^{\circ} \mathrm{C}(\%)$ & $61.8(28.0$ to 125.6$)$ & $67.4(28.0$ to 125.6$)$ & 49.0 (31.1 to 67.4$)$ & $52.2(34.8$ to 67.4$)$ \\
\hline \multicolumn{5}{|l|}{ Prevalence (in \%) of symptoms in the last year } \\
\hline Asthma symptoms (WQ) & 14.6 (1.8 to 36.7$)$ & 11.9 (1.5 to 27.2$)$ & 16.7 (2.7 to 36.7$)$ & 8.5 (3.5 to 18.4$)$ \\
\hline Asthma symptoms (VQ) & 7.5 (0.7 to 19.6$)$ & - & 6.2 (3.8 to 9.8$)$ & - \\
\hline Rhinitis symptoms & 13.7 (1.6 to 39.7$)$ & $6.9(1.5$ to 14.9$)$ & $14.7(6.2$ to 25.5$)$ & 5.7 (3.5 to 11.2 ) \\
\hline Eczema symptoms & $7.6(0.1$ to 19.9$)$ & $7.2(0.7$ to 18.4$)$ & $9.3(1.8$ to 18.9$)$ & $6.6(2.6$ to 18.4$)$ \\
\hline
\end{tabular}

climate and atopic diseases worldwide are adjusted for GNP (available for 144 study centres with climate data and expressed in US dollars). Within Western Europe, GNP is not associated with the prevalence of atopic diseases and was therefore not included in the models involving only European centres. ${ }^{31}$ Due to high collinearity (up to $r=0.85$ ) between the various climatic factors, no attempt was made to calculate multivariate models including more than one climate variable. All independent and outcome variables were summary data on the study centres $(n=144)$ with complete information on climate and GNP that were included in the analyses.
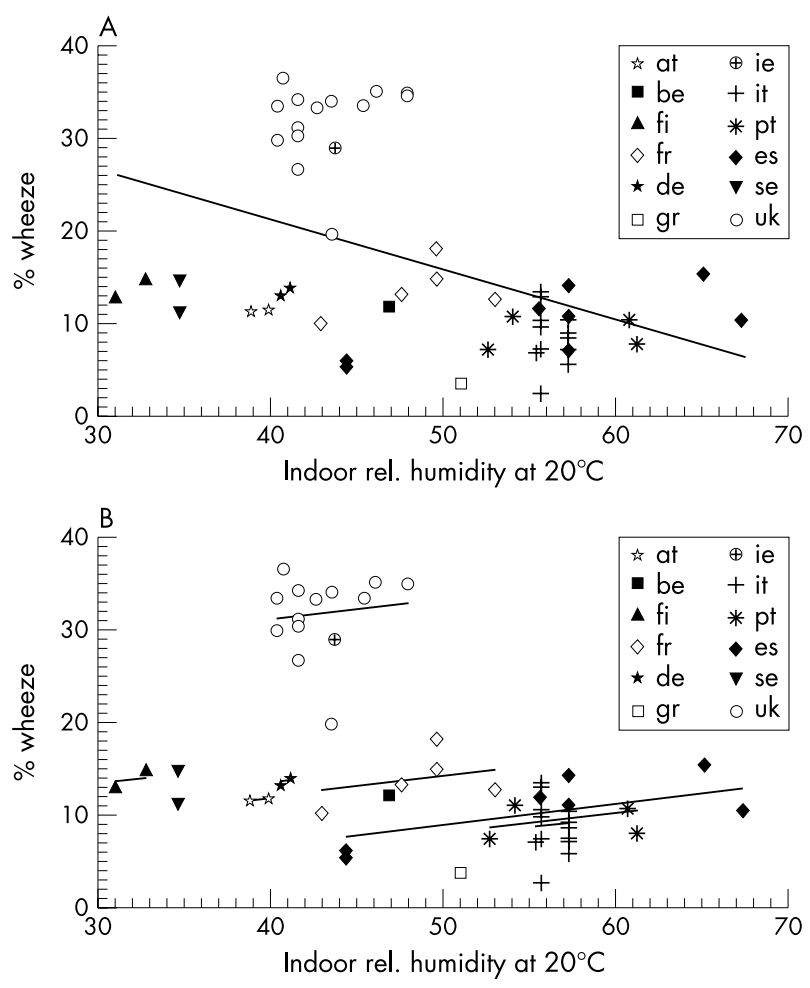

Figure 1 Prevalence of wheeze (assessed by written questionnaire) in relation to indoor relative humidity in 55 study centres in 12 countries in western Europe; results of ordinary least squares and multilevel regression analyses. (A) Ordinary least square regression: original data points and estimated overall regression line. (B) Multilevel regression: original data points and estimated regression lines within country. at, Austria; be, Belgium; fi, Finland; fr, France; de, Germany; ie, Ireland; it, Italy; pt, Portugal; es, Spain, se, Sweden; uk, United Kingdom.

\section{RESULTS}

Table 1 presents characteristics of the study centres worldwide and in Western Europe. The mean altitude was 173 metres for all ISAAC study centres and 97 metres for the centres in Europe. The European centres were located at higher latitude (47.2) and had lower annual means of outdoor temperature $\left(12.3^{\circ} \mathrm{C}\right)$ and indoor relative humidity $(49.0 \%)$ than all centres combined $\left(36.6,15.7^{\circ} \mathrm{C}\right.$, and $61.8 \%$ respectively). The mean and range of the prevalence of atopic symptoms did not differ substantially between all centres worldwide and in those in Western Europe (table 1).

Tables 2 and 3 present the association between climatic factors and the prevalence of asthma symptoms. Altitude was inversely associated with asthma symptoms, assessed by written questionnaire, in both age groups in Western Europe. For example, in Western Europe an increase in altitude of 100 metres was associated with a decrease of $0.88 \%$ (95\% CI $-1.40 \%$ to $-0.36 \%$ ) in the 12 months period prevalence of wheeze in 13-14 year olds. Among all centres worldwide there was a similar tendency in 6-7 year olds, although the $95 \%$ confidence intervals of the regression coefficient do not exclude zero. No association was seen with the annual means of outdoor temperature and outdoor relative humidity, while the lowest monthly means of temperature and relative humidity outdoors were positively related to asthma symptoms in children of both age groups in Europe. The annual variation of outdoor temperature and relative humidity showed a negative association with asthma symptoms in European children. Centres in Europe where the mean outdoor relative humidity drops below $50 \%$ for at least one month per year had a lower asthma prevalence. The annual mean of the estimated indoor relative humidity was positively associated with the prevalence of asthma symptoms in Western Europe, in both age groups and with both instruments (the written and video questionnaires). The lowest monthly mean relative humidity indoors was also positively related to asthma symptoms, assessed by written questionnaire, in European children of both age groups.

No consistent picture emerged for the association between climatic conditions and the prevalence of symptoms of rhinoconjunctivitis (table 4). Some associations were observed, but none of them was found more than oncethat is, for another age group or region. Table 5 presents the associations of the prevalence of symptoms of atopic eczema with climatic conditions. Among the European centres, the prevalence of eczema symptoms in both age groups increased with latitude and decreased with mean annual outdoor temperature. Worldwide, indoor relative humidity was negatively associated with eczema symptoms in 6-7 year 
Table 2 Association of climatic factors with the 12 month period prevalence rates (in \%) of symptoms of asthma, assessed by written questionnaire (WQ), in children; results of the multilevel linear regression analyses

\begin{tabular}{|c|c|c|c|c|}
\hline & \multicolumn{2}{|l|}{ Worldwide* } & \multicolumn{2}{|l|}{ Western Europe } \\
\hline & $\begin{array}{l}13-14 \text { years } \mathrm{RC} \dagger \\
(95 \% \mathrm{Cl})\end{array}$ & $\begin{array}{l}6-7 \text { years RC† } \\
(95 \% \mathrm{Cl})\end{array}$ & $\begin{array}{l}13-14 \text { years } \mathrm{RC} \dagger \\
(95 \% \mathrm{Cl})\end{array}$ & $\begin{array}{l}6-7 \text { years RC† } \\
(95 \% \mathrm{Cl})\end{array}$ \\
\hline Latitude (degrees) & $-0.02(-0.11$ to 0.07$)$ & $-0.02(-0.13$ to 0.08$)$ & $0.18(-0.13$ to 0.49$)$ & $-0.01(-0.26$ to 0.23$)$ \\
\hline \multicolumn{5}{|c|}{ (5) } \\
\hline Mean annual temperature $\left({ }^{\circ} \mathrm{C}\right)$ & $0.06(-0.10$ to 0.23$)$ & $0.06(-0.18$ to 0.31$)$ & $0.37(-0.15$ to 0.89$)$ & $0.12(-0.29$ to 0.54$)$ \\
\hline Annual variation in mean temperature ( $\mathrm{C}$ ) & $-0.31(-1.30$ to 0.69$)$ & $-0.06(-1.38$ to 1.26$)$ & $-5.00(-8.43$ to -1.57$)$ & $-4.10(-6.22$ to -1.98$)$ \\
\hline Lowest monthly mean temperature ( $\mathrm{C})$ & $0.02(-0.07$ to 0.11$)$ & $0.01(-0.12$ to 0.14$)$ & $0.36(0.03$ to 0.69$)$ & $0.31(0.04$ to 0.57$)$ \\
\hline Mean temperature of $\geqslant 1$ month below $0^{\circ} \mathrm{C}$ & $-0.51(-2.97$ to 1.96$)$ & $-1.86(-5.68$ to 1.96$)$ & $-0.96(-7.64$ to 5.73$)$ & $-1.09(-4.61$ to 2.43$)$ \\
\hline \multicolumn{5}{|l|}{ Outdoor relative humidity } \\
\hline Mean annual relative humidity (\%) & $-0.03(-0.11$ to 0.06$)$ & $-0.05(-0.13$ to 0.04$)$ & $0.17(-0.05$ to 0.38$)$ & $0.11(-0.04$ to 0.26$)$ \\
\hline Annual variation in mean relative humidity (\%) & $-0.31(-1.13$ to 0.51$)$ & $-0.12(-0.86$ to 0.62$)$ & $-1.84(-3.06$ to -0.62$)$ & $-1.13(-1.91$ to -0.35$)$ \\
\hline Lowest monthly mean relative humidity (\%) & $0.00(-0.05$ to 0.06$)$ & $0.00(-0.05$ to 0.04$)$ & $0.13(0.04$ to 0.23$)$ & $0.09(0.02$ to 0.15$)$ \\
\hline $\begin{array}{l}\text { Mean relative humidity of } \geqslant 1 \text { month below } 50 \% \\
\text { Indoor relative humidity at } 20^{\circ} \mathrm{C}\end{array}$ & \multicolumn{4}{|c|}{ 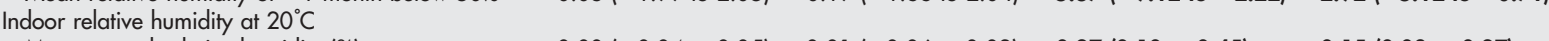 } \\
\hline Mean annual relative humidity (\%) & $0.00(-0.04$ to 0.05$)$ & $-0.01(-0.06$ to 0.03$)$ & $0.27(0.10$ to 0.45$)$ & $0.15(0.03$ to 0.27$)$ \\
\hline Annual variation in mean relative humidity (\%) & $-0.01(-0.43$ to 0.42$)$ & $0.12(-0.22$ to 0.47$)$ & $0.41(-0.68$ to 1.49$)$ & $-0.12(-0.91$ to 0.68$)$ \\
\hline Lowest monthly mean relative humidity (\%) & $0.02(-0.03$ to 0.06$)$ & $0.00(-0.04$ to 0.04$)$ & $0.26(0.05$ to 0.46$)$ & $0.22(0.08$ to 0.36$)$ \\
\hline Mean relative humidity of $\geqslant 1$ month below $50 \%$ & $0.85(-1.21$ to 2.90$)$ & $1.95(-0.20$ to 4.10$)$ & * & * \\
\hline idjusted for GNP. & 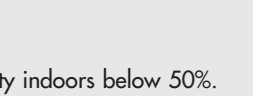 & & & \\
\hline
\end{tabular}

olds. A tendency for a negative association with the lowest monthly mean of indoor relative humidity was observed in European children of the same age.

\section{DISCUSSION}

Before discussion of the findings it is important to address methodological aspects of our study. A strength of this analysis is the relatively large number of study centres worldwide and in Western Europe. All study centres had followed the same study protocol. ${ }^{20}$ In addition, it is possible to check for consistency between findings, although clearly the prevalence estimates are not completely independent. For example, associations that are seen for one instrument, say the written questionnaire on asthma symptoms in 13-14 year olds, can be compared with the findings of the video questionnaire in the same age group, as well as with the findings of the written questionnaire in the younger age group of 6-7 year old children. This check for consistency between age groups and instruments is particularly relevant, because many associations have been investigated and some may have been statistically significant just by chance alone.

A further consideration is that the analyses were conducted for all ISAAC study centres worldwide, and separately just for those located in Western Europe. Besides climatic factors, however, there are huge differences in many other living conditions between the 144 study centres worldwide, for example, nutrition, hygiene, air pollution, etc. Although we did adjust for GNP in our analysis it cannot be expected that all these factors are reasonably reflected by this single measure. In addition, we could not control for potential differences in individual risk factors. Thus, it is possible that climatic influences were missed due to uncontrolled confounding. Among the European centres, in turn, the variation in climatic conditions and in the prevalence of atopic diseases is comparable to the variation worldwide, but the differences

Table 3 Association of climatic factors with the 12 month period prevalence rates (in \%) of symptoms of asthma, assessed by video questionnaire (VQ), in children; results of the multilevel linear regression analyses

\begin{tabular}{|c|c|c|c|c|}
\hline & \multicolumn{2}{|l|}{ Worldwide* } & \multicolumn{2}{|l|}{ Western Europe } \\
\hline & $\begin{array}{l}13-14 \text { years } \mathrm{RC} \dagger \\
(95 \% \mathrm{Cl})\end{array}$ & $\begin{array}{l}6-7 \text { years } \mathrm{RC} \dagger \\
(95 \% \mathrm{Cl})\end{array}$ & $\begin{array}{l}13-14 \text { years } \mathrm{RC} \dagger \\
(95 \% \mathrm{CI})\end{array}$ & $\begin{array}{l}6-7 \text { years } \mathrm{RC} \dagger \\
(95 \% \mathrm{Cl})\end{array}$ \\
\hline Latitude (degrees) & $-0.05(-0.11$ to 0.02$)$ & - & $-0.02(-0.12$ to 0.07$)$ & - \\
\hline Altitude $(100 \mathrm{~m})$ & $0.06(-0.15$ to 0.26$)$ & - & $-0.20(-0.43$ to 0.04$)$ & - \\
\hline \multicolumn{5}{|l|}{ Outdoor temperature } \\
\hline Mean annual temperature $\left({ }^{\circ} \mathrm{C}\right)$ & $0.04(-0.07$ to 0.15$)$ & - & $0.09(-0.06$ to 0.24$)$ & - \\
\hline Annual variation in mean temperature $\left({ }^{\circ} \mathrm{C}\right)$ & $-0.05(-0.74$ to 0.64$)$ & - & $-1.22(-2.49$ to 0.06$)$ & - \\
\hline Lowest monthly mean temperature $\left({ }^{\circ} \mathrm{C}\right)$ & $0.00(-0.06$ to 0.06$)$ & - & $0.07(-0.03$ to 0.18$)$ & - \\
\hline Mean temperature of $\geqslant 1$ month below $0^{\circ} \mathrm{C}$ & $-0.85(-2.41$ to 0.71$)$ & - & $-1.42(-2.87$ to 0.02$)$ & - \\
\hline \multicolumn{5}{|l|}{ Outdoor relative humidity } \\
\hline Mean annual relative humidity (\%) & $-0.06(-0.12$ to 0.00$)$ & - & $0.05(-0.05$ to 0.15$)$ & - \\
\hline Annual variation in mean relative humidity (\%) & $0.25(-0.37$ to 0.88$)$ & - & $-0.63(-1.22$ to -0.03$)$ & - \\
\hline Lowest monthly mean relative humidity (\%) & $-0.03(-0.07$ to 0.01$)$ & - & $0.04(0.00$ to 0.09$)$ & - \\
\hline $\begin{array}{l}\text { Mean relative humidity of } \geqslant 1 \text { month below } 50 \% \\
\text { Indoor relative humidity at } 20^{\circ} \mathrm{C}\end{array}$ & $1.43(0.01$ to 2.86$)$ & - & $-1.22(-2.86$ to 0.42$)$ & - \\
\hline Mean annual relative humidity (\%) & $-0.01(-0.04$ to 0.02$)$ & - & $0.07(0.01$ to 0.14$)$ & - \\
\hline Annual variation in mean relative humidity (\%) & $0.06(-0.24$ to 0.36$)$ & - & $0.15(-0.32$ to 0.62$)$ & - \\
\hline Lowest monthly mean relative humidity (\%) & $0.00(-0.03$ to 0.04$)$ & - & $0.07(0.00$ to 0.13$)$ & - \\
\hline Mean relative humidity of $\geqslant 1$ month below $50 \%$ & $0.38(-1.03$ to 1.79$)$ & - & $\ddagger$ & - \\
\hline
\end{tabular}

*Adjusted for GNP.

†Regression coefficient with $95 \%$ confidence interval.

$\ddagger$ All centres had $\geqslant 1$ month with mean relative humidity indoors below $50 \%$. 
Table 4 Association of climatic factors with the 12 month period prevalence rates (in \%) of symptoms of allergic rhinoconjunctivitis in children; results of the multilevel linear regression analyses

\begin{tabular}{|c|c|c|c|c|}
\hline & \multicolumn{2}{|l|}{ Worldwide $^{*}$} & \multicolumn{2}{|l|}{ Western Europe } \\
\hline & $\begin{array}{l}13-14 \text { years } \mathrm{RC} \dagger \\
(95 \% \mathrm{Cl})\end{array}$ & $\begin{array}{l}\text { 6-7 years } \mathrm{RC} \dagger \\
(95 \% \mathrm{Cl})\end{array}$ & $\begin{array}{l}13-14 \text { years } \mathrm{RC} \uparrow \\
(95 \% \mathrm{CI})\end{array}$ & $\begin{array}{l}\text { 6-7 years } \mathrm{RC} \dagger \\
(95 \% \mathrm{Cl})\end{array}$ \\
\hline Latitude (degree) & $-0.09(-0.18$ to -0.01$)$ & $-0.05(-0.11$ to 0.00$)$ & $0.13(-0.06$ to 0.33$)$ & $0.00(-0.12$ to 0.11$)$ \\
\hline Altitude $(100 \mathrm{~m})$ & $-0.02(-0.30$ to 0.25$)$ & $-0.05(-0.26$ to 0.16$)$ & & .53 to 0.14$)$ \\
\hline \multicolumn{5}{|l|}{ Outdoor temperature } \\
\hline Mean annual temperature ( ${ }^{\circ} \mathrm{C}$ ) & $0.21(0.03$ to 0.39$)$ & $0.11(-0.02$ to 0.25$)$ & $0.01(-0.36$ to 0.39$)$ & $-0.05(-0.22$ to 0.12$)$ \\
\hline Annual variation in mean temperature ( ${ }^{\circ} \mathrm{C}$ ) & $-0.12(-1.25$ to 1.01$)$ & $-0.20(-1.03$ to 0.63$)$ & $-2.87(-5.81$ to 0.06$)$ & -2.23 ( -3.85 to -0.6 \\
\hline Lowest monthly mean temperature $\left({ }^{\circ} \mathrm{C}\right)$ & $0.06(-0.04$ to 0.17$)$ & $0.04(-0.04$ to 0.12$)$ & $0.12(-0.15$ to 0.39$)$ & $0.07(-0.09$ to 0.24$)$ \\
\hline Mean temperature of $\geqslant 1$ month below $0^{\circ} \mathrm{C}$ & $-0.84(-3.55$ to 1.87$)$ & $-1.04(-3.16$ to 1.09$)$ & $-1.39(-5.60$ to 2.82$)$ & $0.45(-1.16$ to 2.06$)$ \\
\hline \multicolumn{5}{|l|}{ Outdoor relative humidity } \\
\hline Mean annual relative humidity (\%) & $-0.10(-0.19$ to -0.01$)$ & $-0.03(-0.09$ to 0.03$)$ & $0.12(-0.06$ to 0.30$)$ & $0.06(-0.03$ to 0.16$)$ \\
\hline Annual variation in mean relative humidity (\%) & $0.15(-0.72$ to 1.02$)$ & $-0.13(-0.64$ to 0.39$)$ & $-0.60(-1.82$ to 0.62$)$ & $-0.62(-1.33$ to 0.09$)$ \\
\hline Lowest monthly mean relative humidity (\%) & $-0.05(-0.10$ to 0.01$)$ & $-0.01(-0.04$ to 0.03$)$ & $0.06(-0.04$ to 0.15$)$ & 0.06 (0.01 to 0.11$)$ \\
\hline Mean relative humidity of $\geqslant 1$ month below $50 \%$ & $1.52(-0.65$ to 3.68$)$ & $0.65(-0.61$ to 1.92$)$ & $-2.54(-6.34$ to 1.27$)$ & $-1.86(-3.69$ to -0.0 \\
\hline \multicolumn{5}{|l|}{ Indoor relative humidity at $20^{\circ} \mathrm{C}$} \\
\hline Mean annual relative humidity (\%) & $0.03(-0.02$ to 0.07$)$ & $0.01(-0.02$ to 0.03$)$ & $0.07(-0.09$ to 0.24$)$ & $0.03(-0.05$ to 0.12$)$ \\
\hline Annual variation in mean relative humidity (\%) & $0.13(-0.29$ to 0.55$)$ & $0.10(-0.13$ to 0.33$)$ & $-0.61(-1.64$ to 0.42$)$ & $-0.21(-0.71$ to 0.29$)$ \\
\hline Lowest monthly mean relative humidity (\%) & $0.04(-0.01$ to 0.08$)$ & $0.01(-0.02$ to 0.03$)$ & $0.18(0.01$ to 0.36$)$ & $0.06(-0.03$ to 0.16$)$ \\
\hline Mean relative humidity of $\geqslant 1$ month below $50 \%$ & $-0.77(-3.06$ to 1.52$)$ & $0.20(-1.20$ to 1.60$)$ & $\ddagger$ & $\ddagger$ \\
\hline
\end{tabular}

*Adjusted for GNP.

tRegression coefficient with $95 \%$ confidence interval.

$\ddagger$ All centres had $\geqslant 1$ month with mean relative humidity indoors below $50 \%$.

in living conditions unrelated to climate are much smaller. ${ }^{31}$ This could explain why several associations which were strong and consistent for the European centres could not be detected on the worldwide scale.

Since our data on long term climatic conditions were published in 1984, while the information on disease prevalence was collected between 1992 and 1996, one could argue that changes in climate may have distorted the associations under investigation. However, during the past 50 years the global average surface temperature has increased by $0.6^{\circ} \mathrm{C}^{32}$ This magnitude is relatively small compared to the differences in climate between study centres, and therefore we think that it is unlikely that our analysis was substantially biased due to climate change.

An important methodological issue is that many countries had more than one centre. Causal factors which are unrelated to climate may also differ strongly by country, and it was therefore important to adjust for country effects in the statistical analysis. The use of the multilevel models that take country effects into account strengthens our study substantially. The presented results largely reflect the within country variability. This reduced the potential for bias since the variation of relevant but unmeasured living conditions is likely to be smaller within countries than between the countries. It also reduces the potential for bias due to problems with translation of the questionnaire. The potential for misleading results if the country effects are not taken into account is shown by fig $\mathrm{l}$. It is noteworthy, however, that a similar reversal after adjustment for country effects was not seen for any other association under investigation. Interestingly, the association between the estimated annual mean of the indoor relative humidity and the prevalence of asthma symptoms assessed by video questionnaire showed a positive association even without adjustment for country. This suggests that problems with the translation of the questionnaire may have occurred and shows the value of the

Table 5 Association of climatic factors with the 12 month period prevalence rates (in \%) of symptoms of atopic eczema in children; results of the multilevel linear regression analyses

\begin{tabular}{|c|c|c|c|c|}
\hline & \multicolumn{2}{|l|}{ Worldwide* } & \multicolumn{2}{|l|}{ Western Europe } \\
\hline & $\begin{array}{l}13-14 \text { years } \mathrm{RC} \dagger \\
(95 \% \mathrm{Cl})\end{array}$ & $\begin{array}{l}6-7 \text { years } \mathrm{RC} \dagger \\
(95 \% \mathrm{Cl})\end{array}$ & $\begin{array}{l}13-14 \text { years } \mathrm{RC} \dagger \\
(95 \% \mathrm{Cl})\end{array}$ & $\begin{array}{l}6-7 \text { years } \mathrm{RC} \dagger \\
(95 \% \mathrm{Cl})\end{array}$ \\
\hline Latitude (degree) & $0.00(-0.05 ; 0.04)$ & $0.05(-0.01 ; 0.11)$ & $0.16(0.01 ; 0.31)$ & $0.29(0.07 ; 0.50)$ \\
\hline Altitude $(100 \mathrm{~m})$ & $0.06(-0.08 ; 0.19)$ & $0.03(-0.18 ; 0.24)$ & $0.05(-0.23 ; 0.34)$ & $-0.04(-0.51 ; 0.42)$ \\
\hline \multicolumn{5}{|l|}{ Outdoor temperature } \\
\hline Mean annual temperature $\left({ }^{\circ} \mathrm{C}\right)$ & $-0.01(-0.09 ; 0.07)$ & $-0.14(-0.29 ;-0.01)$ & $-0.29(-0.55 ;-0.03)$ & $-0.45(-0.83 ;-0.08)$ \\
\hline Annual variation in mean temperature $\left({ }^{\circ} \mathrm{C}\right)$ & $0.18(-0.36 ; 0.72)$ & $0.56(-0.17 ; 1.29)$ & $-0.16(-1.93 ; 1.61)$ & $-0.53(-3.52 ; 2.45)$ \\
\hline Lowest monthly mean temperature $\left({ }^{\circ} \mathrm{C}\right)$ & $-0.01(-0.06 ; 0.03)$ & $-0.08(-0.15 ;-0.01)$ & $-0.10(-0.28 ; 0.07)$ & $-0.17(-0.48 ; 0.13)$ \\
\hline Mean temperature of $\geqslant 1$ month below $0^{\circ} \mathrm{C}$ & $0.18(-1.01 ; 1.36)$ & $1.35(-1.11 ; 3.81)$ & $0.52(-2.72 ; 3.75)$ & $1.99(-2.02 ; 5.99)$ \\
\hline \multicolumn{5}{|l|}{ Outdoor relative humidity } \\
\hline Mean annual relative humidity (\%) & $-0.02(-0.07 ; 0.02)$ & $-0.03(-0.08 ; 0.02)$ & $0.10(0.00 ; 0.20)$ & $0.08(-0.09 ; 0.24)$ \\
\hline Annual variation in mean relative humidity (\%) & $0.43(-0.05 ; 0.91)$ & $0.38(-0.03 ; 0.80)$ & $-0.11(-0.73 ; 0.52)$ & $0.17(-0.89 ; 1.23)$ \\
\hline Lowest monthly mean relative humidity $(\%)$ & $-0.02(-0.05 ; 0.01)$ & $-0.02(-0.05 ; 0.01)$ & $0.03(-0.02 ; 0.08)$ & $0.01(-0.07 ; 0.09)$ \\
\hline $\begin{array}{l}\text { Mean relative humidity of } \geqslant 1 \text { month below } 50 \% \\
\text { Indoor relative humidity at } 20^{\circ} \mathrm{C}\end{array}$ & $0.77(-0.35 ; 1.89)$ & $0.71(-0.33 ; 1.76)$ & $0.03(-1.79 ; 1.85)$ & $-0.57(-3.44 ; 2.29)$ \\
\hline Mean annual relative humidity (\%) & $-0.01(-0.03 ; 0.01)$ & $-0.03(-0.05 ;-0.01)$ & $0.00(-0.10 ; 0.09)$ & $-0.11(-0.24 ; 0.03)$ \\
\hline Annual variation in mean relative humidity (\%) & $-0.05(-0.30 ; 0.20)$ & $0.12(-0.07 ; 0.31)$ & $-0.01(-0.53 ; 0.50)$ & $-0.19(-0.99 ; 0.60)$ \\
\hline Lowest monthly mean relative humidity (\%) & $0.00(-0.02 ; 0.02)$ & $-0.02(-0.04 ; 0.00)$ & $-0.01(-0.11 ; 0.10)$ & $-0.11(-0.27 ; 0.05)$ \\
\hline Mean relative humidity of $\geqslant 1$ month below $50 \%$ & $0.79(-0.28 ; 1.86)$ & $1.36(0.19 ; 2.54)$ & $\ddagger$ & $\ddagger$ \\
\hline
\end{tabular}

${ }^{*}$ Adjusted for GNP.

†Regression coefficient with $95 \%$ confidence interval.

$\ddagger$ All centres had $\geqslant 1$ month with mean relative humidity indoors below $50 \%$. 
video questionnaire as an additional instrument to assess asthma prevalence. Finally, it is important to keep in mind that prevalence reflects both the incidence and duration of symptoms or diseases.

We observed an inverse association between the prevalence of asthma symptoms and the altitude of the study area, an observation which is in line with previous reports. ${ }^{12} 1433$ Mean annual outdoor temperature and outdoor relative humidity were not associated with the prevalence of asthma symptoms. Thus, our data could not confirm a recent study from New Zealand, which found a positive association between the annual mean temperature and the prevalence of asthma symptoms in adults. ${ }^{19}$ However, we showed a positive relation between the lowest monthly mean temperature and asthma symptoms in both age groups of European children. The latter may be seen in contrast with observations from short term effects on asthma symptoms, which have shown that low temperature and falls in temperature are associated with exacerbation of asthma symptoms. ${ }^{5834}$ It must be kept in mind, however, that the factors that cause aggravation or exacerbation of symptoms may differ from those that determine the overall prevalence of the disease.

In addition, a recent analysis of data from the European Community Respiratory Health Study (ECRHS), a worldwide study on asthma prevalence in adults, also showed a positive association between the prevalence of asthma symptoms (shortness of breath, tightness in the chest, and asthma medication) and the temperature of the coldest month, not with mean annual temperature. ${ }^{35}$ The prevalence of hay fever was not found to be associated with climatic conditions. This paper was based on 48 study centres, mostly in Europe, and used climate data from the "Global Historical Climate Network". Data on humidity were unfortunately not included in the analyses. ${ }^{35}$

In our study, we found in Western Europe a positive association between levels of indoor relative humidity and the prevalence of asthma symptoms in both age groups and according to both instruments. A limitation of this finding is that the indoor relative humidity was not directly measured, but was estimated indirectly using outdoor relative humidity and temperature. To derive these estimates we assumed an indoor temperature of $20^{\circ} \mathrm{C}$, which may not be correct for all homes. However, the observed associations with asthma symptoms were similar when we assumed different indoor temperatures, for example, $18^{\circ} \mathrm{C}$ instead of $20^{\circ} \mathrm{C}$. In addition, while outdoor relative humidity is a strong determinant of indoor relative humidity, it is known that the latter is also influenced by building characteristics, such as ventilation or air conditioning. ${ }^{18} 36$ These factors, however, are likely to differ much less within countries than between countries. In addition, air conditioning is still very rare in private homes of children in Western Europe. Therefore, we think that it is unlikely that systematic bias can explain the observed positive relation with asthma symptoms.

The mechanisms, directly or indirectly, by which indoor relative humidity may affect the manifestation of asthma in children are not clear. At least two aspects may be important in this context. The indoor relative humidity is an important factor influencing the infestation with house dust mites in homes. ${ }^{18}{ }^{36-38}$ However, while atopic sensitisation against house dust mites is associated with asthma in children, evidence to support that exposure to house dust mites is causally related to the incidence of asthma is very limited. ${ }^{38-40}$ Home dampness and moulds are other factors that may be influenced by levels of indoor relative humidity. These have been associated with the prevalence of asthma symptoms and bronchial hyperresponsiveness in many studies ${ }^{38} 41$ and could be factors by which indoor relative humidity affects the prevalence of asthma symptoms.
The annual variation of the outdoor temperature and relative humidity was inversely related to the prevalence of asthma symptoms. A similar tendency was also observed in the New Zealand study on adults. ${ }^{19}$ It is not clear whether these associations reflect true causal relations or correlates of other important determinants. Little is known about the relation between long term climatic conditions and the prevalence of allergic rhinitis, ${ }^{22}$ but the findings from our study do not suggest that climate, at least in children, plays a major role.

Previous studies of regional differences in the prevalence of eczema have been hampered by low numbers of centres, mostly within a country, in which surveys had been conducted with comparable methodology. ${ }^{42-44}$ This is the first international study involving many countries and centres. The prevalence of eczema symptoms was positively associated with latitude and negatively associated with mean annual temperature. This association was seen in both age groups in Europe and also among 6-7 year olds worldwide. It is possible, however, that latitude and temperature affect the prevalence of eczema only indirectly, due to changes in behaviour and differences in sun exposure. We also found a tendency of an inverse association between indoor relative humidity and the prevalence of eczema in 6-7 year old children. A potential role of indoor relative humidity has also been suggested by others ${ }^{45}$ and may deserve further investigation.

In conclusion, this is the first ecological study of the relation between climate and the prevalence of asthma, allergic rhinoconjunctivitis, and atopic eczema in children on a worldwide scale. The prevalence of asthma symptoms was found to be inversely related to altitude and the annual variation in temperature and relative humidity outdoors. The estimated levels of indoor relative humidity, in turn, were positively associated with asthma symptoms. No clear relation emerged between the prevalence of allergic rhinoconjunctivitis and climatic factors. The prevalence of eczema symptoms was positively associated with latitude and negatively associated with mean annual outdoor temperature. There was also a tendency for a negative association of eczema symptoms with mean relative humidity indoors. These findings suggest that climate may affect the prevalence of asthma and atopic eczema in children. This may also have implications for the assessment of potential health effects due to climate change.

\section{Authors' affiliations}

S K Weiland, P Rzehak, Department of Epidemiology, University of Ulm, Ulm, Germany

A Hüsing, Department of Medical Informatics, Biometrics und Epidemiology, University of Bochum, Germany

D P Strachan, St George's Hospital Medical School, London, UK N Pearce, Massey University, Wellington, New Zealand

The study was funded in part by the Innovative Medizinische Forschung (IMF) programme (WE-1-1-II/96-3) of the University of Münster, Germany

\section{REFERENCES}

1 Tromp SW. Influence of weather and climate on asthma and bronchitis. Rev Allergy 1968;22:1027-44.

2 Cullen KJ. Climate and chest disorders in schoolchildren. BMJ 1972;4:65-7.

3 Carey MJ, Cordon I. Asthma and climatic conditions: experience from Bermuda, an isolated island community. BMJ 1986;293:843-4.

4 Dales RE, Schweitzer I, Toogood JH, et al. Respiratory infections and the autumn increase in asthma morbidity. Eur Respir J 1996;9:72-7.

5 Celenza A, Fothergill J, Kupek E, et al. Thunderstorm associated asthma: a detailed analysis of environmental factors. BMJ 1996;312:604-7.

6 Harju T, Tuuponen T, Keistinen T, et al. Seasonal variations in hospital treatment periods and deaths among adult asthmatics. Eur Respir J 1998; 12:1362-5. 
7 Newson R, Strachan D, Archibald E, et al. Effect of thunderstorms and airborne grass pollen on the incidence of acute asthma in England, 1990-94 Thorax 1997;52:680-5.

8 Epton M, Martin I, Graham P. Climate and aeroallergen levels in asthma: a 12 month prospective study. Thorax 1997;52:528-34.

9 Lipsett M, Hurley S, Ostro B. Air pollution and emergency room visits for asthma in Santa Clara county, California. Environ Health Perspect 1997; 105:216-22.

10 Newson R, Strachan D, Archibald E, et al. Acute asthma epidemics, weather and pollen in England, 1987-1994. Eur Respir J 1998;11:694-701.

11 Tanaka H, Honma S, Nishi M, et al. Acid fog and hospital visits for asthma: an epidemiological study. Eur Respir J 1998;11:1301-6.

12 Charpin D, Kleisbauer J, Lanteaume A. Asthma and allergy to house dust mites in populations living in high altitudes. Chest 1988;93:758-61.

13 Peat JK, Woolcock AJ. Sensitivity to common allergens: relation to respiratory symptoms and bronchial hyper-responsiveness in children from three different climatic areas of Australia. Clin Exp Allergy 1991;21:573-81.

14 Charpin D, Birnbaum J, Haddi E. Altitude and allergy to house dust mites. Am Rev Respir Dis 1991;143:983-6.

15 Bjornsson E, Plaschke P, Norrman E, et al. Symptoms related to asthma and chronic bronchitis in three areas of Sweden. Eur Respir J 1994;7:2146-53.

16 Peat JK, Toelle BG, Gray EJ, et al. Prevalence and severity of childhood asthma and allergic sensitisation in seven climatic regions of New South Wales. Med J Aust 1995; 163:22-6.

17 Echechipia S, Ventas P, Audicana M, et al. Quantitation of major allergens in dust samples from urban populations collected in different seasons in 2 climatic areas of the Basque region (Spain). Allergy 1995;50:478-82.

18 Munir AKM, Bjorksten B, Einarsson R, et al. Mite allergens in relation to home conditions and sensitization of asthmatic-children from 3 climatic regions. Allergy 1995;50:55-64.

19 Hales S, Lewis S, Slater T, et al. Prevalence of adult asthma symptoms in relation to climate in New Zealand. Environ Health Perspect 1998;106:607-10.

20 Asher MI, Keil U, Anderson HR, et al. International Study of Asthma and Allergies in Childhood-ISAAC: rationale and methods. Eur Respir $J$ 1995;8:483-91.

21 Asher MI, Weiland SK, on behalf of the ISAAC Steering Committee. The International Study of Asthma and Allergies in Childhood (ISAAC). Clin Exp Allergy 1998;28:52-66.

22 Strachan D, Sibbald B, Weiland SK, et al. Worldwide variation in prevalence of symptoms of allergic rhinoconjunctivitis in children: The International Study of Asthma and Allergies in Childhood (ISAAC). Pediatr Allergy Immunol 1997;8:161-76.

23 The International Study of Asthma and Allergies in Childhood (ISAAC) Steering Committee. Worldwide variations in prevalence of symptoms of asthma, allergic rhinoconjunctivitis and atopic eczema: ISAAC. Lancet 1998;351:1225-32.

24 The International Study of Asthma and Allergies in Childhood (ISAAC) Steering Committee. Worldwide variations in prevalence of asthma symptoms: The International Study of Asthma and Allergies in Childhood (ISAAC). Eur Respir J 1998;12:315-35.
25 Williams $\mathbf{H}$, Robertson C, Stewart A, et al. Worldwide variations in prevalence of symptoms of atopic eczema in the International Study of Asthma and Allergies in Childhood. J Allergy Clin Immunol 1999;103:125-38.

26 Gibson PG, Henry R, Shah S, et al. Validation of the ISAAC video questionnaire (AVQ3.0) in adolescents from a mixed ethnic background. Clin Exp Allergy 2000;30:1181-7.

27 Pearce EA, Smith G. World weather guide. London, Melbourne, Sydney, Auckland, Johannesburg: Hutchinson, 1984.

28 Roedel W. Physik unserer Umwelt: die Atmosphäre. Berlin: Springer, 1994:186-7.

29 Littell RC, Miliken GA, Stroup WW, et al. SAS system for mixed models. Cary, NC: SAS Institute Inc, 1996.

30 Goldstein H. Multilevel statistical models. Kendall's advanced theory of statistics, 2nd edn. London: Arnold, 1995.

31 Stewart AW, Mitchell EA, Pearce N, et al. The relationship of per capita gross national product to the prevalence of symptoms of asthma and other atopic diseases in children. Int J Epidemiol 2001;303:173-9.

32 Patz JA, Kovats RS. Hotspots in climate change and human health. BMJ 2002;9, 25:1094-8.

33 Allegra L, Cogo A, Legnani D, et al. High-altitude exposure reduces bronchial responsiveness to hypoosmolar aerosol in lowland asthmatics. Eur Respir J 1995;8: 1842-6.

34 Larsson K, Ohlsen P, Larsson L, et al. High prevalence of asthma in crosscountry skiers. BMJ 1993;307:1326-9.

35 Verlato G, Calabrese R, De Marco R. Correlation between asthma and climate in the European Community Respiratory Health Survey. Arch Environ Health 2002;57:48-52.

36 Lintner TJ, Brame KA. The effects of season, climate, and air-conditioning on the prevalence of dermatophagoides mite allergens in household dust. J Allergy Clin Immunol 1993;91:862-7.

37 Arlian L. Water balance and humidity requirements of house dust mites. Exp Appl Acarol 1992;16:15-35.

38 Peat JK, Dickerson J, Li J. Effects of damp and mould in the home on respiratory health: a review of the literature. Allergy 1998;53:120-8.

39 Pearce N, Douwes J, Beasley R. Is allergen exposure the major primary cause of asthma? Thorax 2000;55:424-31.

40 Lau S, Illi S, Sommerfeld C, et al. Early exposure to house-dust mite and cat allergens and development of childhood asthma: a cohort study. Lancet 2000;356:1392-7.

41 Nicolai T, Illi S, von Mutius E. Effect of dampness at home in childhood on bronchial hyperreactivity in adolescence. Thorax 1998;53:1035-40.

42 Schultz Larsen F, Diepgen T, Svensson A. The occurrence of atopic dermatitis in north Europe: an international questionnaire study. J Am Acad Dermatol 1996;34:760-4.

43 Poysa L, Korppi M, Pietikainen M, et al. Asthma, allergic rhinitis and atopic eczema in Finnish children and adolescents. Allergy 1991;46:161-5.

$44 \mathrm{McNally}$ NJ, Williams HC, Phillips DR, et al. Is there a geographical variation in eczema prevalence in the UK? Evidence from the 1958 British Birth Cohort Study. Br J Dermatol 2000;142:712-20

45 Eberlein-Konig B, Spiegl A, Przybilla B. Change of skin roughness due to lowering air humidity in climate chamber. Acta Derm Venereol 1996;76:447-9. 